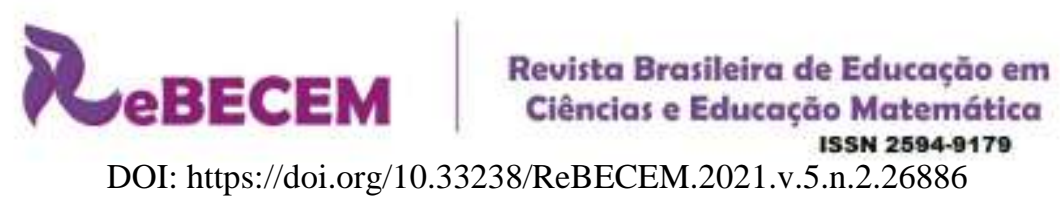

\title{
RESENHA DO LIVRO A FORMAÇÃ̃ MATEMÁTICA DO PROFESSOR: LICENCIATURA E PRÁTICA DOCENTE ESCOLAR
}

\section{BOOK REVIEW THE TEACHER'S MATHEMATICAL TRAINING: SCHOOL TEACHING LICENSING AND PRACTICE}

\author{
Franklin Fernando Ferreira Pachêco ${ }^{1}$ \\ Alan Gustavo Ferreira ${ }^{2}$
}

O livro A formação matemática do professor: licenciatura e prática docente escolar $^{3}$, produzido pelos autores Plínio Cavalcanti Moreira e Maria Manuela Martins Soares David, integra a coleção Tendências em Educação Matemática. Esses autores, pesquisadores em Educação Matemática com experiência profissional no ensino superior, nessa obra, abordam uma concepção para o processo de formação inicial do professor de matemática, apoiada na prática de professores na Educação Básica, sobre o reconhecimento (distinção e articulação) entre o saber da matemática escolar e o ensino da matemática acadêmica. Para isso, de modo a confrontá-las, apoiam-se no conceito de número (naturais, racionais e reais).

De modo a situar os leitores da obra, as discussões são iniciadas sobre o contexto da licenciatura no Brasil que se apoiava no modelo de formação inicial do professor como $3+1$. Esse formato, na atualidade, já superado na maioria dos cursos das distintas licenciaturas, não apenas no curso superior de formação de futuros professores de matemática, era conhecido por bacharelado + didática, ou seja, três anos de aprimoramento de disciplinas específicas e um ano referente ao aperfeiçoamento de caráter pedagógico. Com as mudanças de estrutura dos cursos das licenciaturas, tornouse insuficiente formar professores no modelo $3+1$. Seria possível essa perspectiva de formação inicial de professores ainda sobreviver em pleno século XXI?

\footnotetext{
${ }^{1}$ Doutorando em Educação Matemática e Tecnológica (UFPE). Universidade Federal de Pernambuco (UFPE), Recife, Pernambuco, Brasil. E-mail: pacheco.franklin9@gmail.com.

${ }^{2}$ Doutorando em Educação Matemática e Tecnológica (UFPE). Universidade Federal de Pernambuco (UFPE), Recife, Pernambuco, Brasil. E-mail: alan.Gustavo@ @otmail.com.

${ }^{3}$ MOREIRA, P. C.; DAVID, M. M. M. S. A Formação matemática do Professor: licenciatura e prática docente escolar. $2^{\mathrm{a}}$ ed. Belo Horizonte: Autêntica, 2018.
} 
No Brasil, de acordo com Giraldo (2018), apoiado pelas discussões de Moreira (2012), a maioria dos cursos de licenciatura em matemática relegaram o método de formação $3+1$, porém seus conteúdos estão organizados em dois polos, sendo eles: "conteúdo matemático" e "pedagogia", vivenciados em paralelos, mas sem interligações. Para o senso comum, em sua grande maioria, um professor de matemática considerado bom é o que detém de grande saber sobre sua área específica de conhecimento. Apesar disso, essa realidade nem sempre ocorre. Quais reflexões um profissional que concebe muito conhecimento matemático, mas não possui conhecimentos didáticos pode promover para seus alunos? Como o professor de matemática pode aprimorar sua metodologia de ensino? Por isso, a relevância das disciplinas pedagógicas, pois são elas que propiciam aos futuros professores reflexões sobre como e de que modo aprimorar sua metodologia de ensino no cotidiano escolar.

Quais limitações o modelo bacharelado + didática poderia propiciar na postura dos formandos do curso da licenciatura em matemática? A tentativa de superar esse contexto de formação de professores já permite ressaltar que ele era e seria na atualidade insuficiente para suprir a necessidade de profissionais em pleno século XXI. Uma das possíveis limitações seria o despreparo metodológico dos profissionais para o processo de ensino com seus alunos, ou seja, a sua ênfase prática seria em uma abordagem internalizada de sua formação acadêmica anterior (na maioria dos casos centrada na repetição de métodos de seus professores). Essa ruptura, de modo essencial, portanto, possibilitou aos cursos de formação inicial de professores propor disciplinas mais diversificadas (sociologia, filosofia, etc.) que contemplassem um olhar mais crítico e reflexivo sobre a prática de ensino, e mais humana.

De modo a dar suporte à concepção de formação matemática do professor, os autores da obra diferenciam e caracterizam a Matemática Acadêmica e a Matemática Escolar, ressaltando relações entre elas por meio das discussões de Chervel (1990) e Chevallard (1991). Frisam ainda que a ênfase do texto supera a perspectiva de Chervel e Chevallard.

A Matemática Acadêmica se refere ao conhecimento que é produzido e percebido pelos matemáticos e a Matemática Escolar integra o conjunto de saberes direcionados ao processo de ensino e de aprendizagem da matemática na Educação Básica. Uma distinção entre elas, de total pertinência, é ressaltar que enquanto na Matemática Acadêmica as demonstrações são ancoradas com forte teor científico por meio das definições e teoremas, na Matemática Escolar o rigor não é o mesmo 


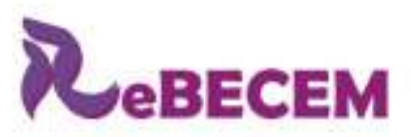

Revista Brasileira de Educaçăo em

Ciências e Educação Matemática

DOI: https://doi.org/10.33238/ReBECEM.2021.v.5.n.2.26886

(demonstrar matematicamente), mas sim prezar pela aprendizagem dos conhecimentos matemáticos na Educação Básica, por meio de justificativas, de modo a usá-la de forma pertinente e atribuir sentido ao seu uso na vida social e escolar. Por isso, nesse sentido, é possível compreender a distinção entre a Matemática Acadêmica (matemático) e a Matemática Escolar (presente no âmbito escolar) (MOREIRA; DAVID, 2018).

Outro argumento interessante apresentado pelos autores é sobre o lugar do erro nas formas do conhecimento matemático (Matemática Acadêmica e Matemática Escolar). O erro na Matemática Acadêmica é considerado como uma oposição a uma sentença verdadeira, enquanto que na Matemática Escolar pode ser um apoio para a prática do professor a fim de trabalhar lacunas com os alunos a leva-los a superação e ao êxito (aprendizagem).

A Matemática Escolar é construída por meio de múltiplos condicionantes: currículo prescrito, conhecimento pedagógico dos conteúdos, saberes e os não saberes relacionados à prática do professor de matemática. De maneira pertinente, e de forma a diferenciar as características e funcionalidades dos condicionantes, os autores da obra elencam que o currículo é um produto social que se adequa às lutas políticas, socioculturais e econômica a fim de estabelecer um processo de escolarização centrado na promoção da aprendizagem da realidade do seu público. Por exemplo, a Base Nacional Comum Curricular/BNCC (BRASIL, 2018), o documento elaborado para nortear as propostas curriculares (municípios, estados, etc.) na Educação Básica, elenca uma base (mínimo) para que a educação escolar nacional seja conduzida de maneira igualitária; os conhecimentos pedagógicos dos conteúdos são as sistematizações dos conteúdos por meio das práticas pedagógicas escolares; os saberes das ações pedagógicas referem-se a qualificação profissional (conhecimentos, habilidades, e competência) que podem ser usadas para promover o processo de ensino; e os não saberes são os saberes trabalhados de maneira inadequada no curso superior ao considerar o contexto como eles são contemplados na Educação Básica.

Esses condicionantes, em associação, são os elementos que promovem a integração dos distintos saberes à Matemática Escolar, assim, portanto, possibilitando o processo de ensino e de aprendizagem dos conhecimentos da matemática contemplando os polos: aluno- saber- professor. É mediante essa interação que a lógica da Matemática Acadêmica é adaptada para o processo de ensino e de aprendizagem no ambiente da sala de aula. 
Dessa forma, é interessante refletir que a formação inicial do professor de matemática deve estar ancorado na articulação e diferenciação entre os conhecimentos da Matemática Acadêmica e Matemática Escolar. Assim, deve-se compreender os saberes de formação e as questões práticas como saberes complementares. Nesse tocante, os autores da obra apresentam questões relativas ao conhecimento matemático sobre os números (naturais, racionais e reais), situações que o professor se confronta direta ou indiretamente, na sua prática docente no ambiente da sala de aula.

Os números naturais estão propostos para serem contemplados a partir do $1^{\circ}$ ano do ensino fundamental (BRASIL, 2018). Por isso, em relação à compreensão das quatros operações, os autores destacam que os cursos de formação de professores para os anos iniciais podem ser favorecidos mais que o da licenciatura em Matemática, pois são nos primeiros anos escolares que se iniciam as discussões sobre as operações básicas (adição, subtração, divisão e multiplicação). De forma a não existir uma descontinuidade entre conhecimentos por parte dos alunos, o professor de matemática nos anos finais do ensino fundamental deve compreender as possíveis dificuldades dos alunos sobre o objeto matemático a fim de trabalhar sobre elas de modo a propiciar aprendizagem. Advindo desse contexto, os conhecimentos dos professores não devem ser resumidos à Matemática Acadêmica porque no âmbito educacional eles lidarão com distintos públicos (alunos) que possuem estágios de aprendizagens diversificados, para aprender a Matemática. Por isso, a relevância do diálogo como entendimento dos conhecimentos prévios e metodologias que busquem estimular a compreensão dos alunos para aprender novos conhecimentos.

No processo da formação dos professores de matemática, os números racionais podem ser vislumbrados como um objeto matemático simples. Para se opor a essa ideologia, os autores da obra destacam que embora seja aparentemente simples, a construção do conceito de números racionais pode ser compreendida como uma das mais complexas na educação escolar. Uma das possíveis complexidades para a compreensão desse conhecimento matemático, por exemplo, esteja em associar a representação desse número a algum contexto prático de sua vida diária.

O professor de matemática deve compreender os números reais enquanto número, pois, no âmbito escolar, o conceito de número é perpassado por contextos de elaboração e reelaboração. Os autores da obra frisam que na escola, até chegar no conceito de números reais, são estudados os conjuntos numéricos (naturais, inteiros e racionais). $\mathrm{Na}$ abordagem do curso da licenciatura, o "[...] conjunto dos números reais é 


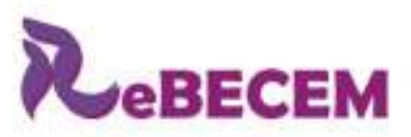

Revista Brasileira de Educaçăo em

Ciências e Educação Matemática

ISSN 2594-9179

DOI: https://doi.org/10.33238/ReBECEM.2021.v.5.n.2.26886

definido como (qualquer) corpo ordenado completo e não se retorna mais à questão da incomensurabilidade" (MOREIRA; DAVID, 2018, p. 90). Partindo dessa premissa, o conhecimento sobre os conjuntos numéricos (racionais, inteiros e reais) contemplados na licenciatura em matemática não são contemplados em sua totalidade no ambiente escolar.

Nas discussões finais, de maneira pertinente, os autores abordam que é possível articular de distintas formas o processo de formação da licenciatura em matemática com a prática escolar. Citam, por exemplo, que os licenciandos ao se formarem voltam à escola como profissional regidos de novos conhecimentos adquiridos ao longo de sua formação inicial. Saberes e não saberes são considerados novos porque ao longo da formação do professor, eles adaptaram, criticaram, reformularam e substituíram saberes.

Uma outra discussão é sobre a maneira como os licenciandos vêm realizando suas ações pedagógicas no ambiente da sala de aula. Sobre isso, os autores pontuam que a formação inicial não deu, em sua totalidade, um aporte para eles desenvolverem suficientemente reflexões e preparação para discussões no ambiente da sala de aula. Essa realidade na formação inicial (teoria e prática), ao não serem vivenciadas de maneira interligadas, podem propiciar uma qualificação com possíveis lacunas que acarretará falhas em sua ação pedagógica.

A leitura dessa obra, portanto, propicia ao leitor reflexões sobre como deveria ocorrer a formação inicial dos professores (teoria e prática), saberes e não saberes essenciais para o seu trabalho no ambiente da sala de aula e uma ampla discussão sobre pesquisas realizadas em torno dos números naturais, racionais e reais.

Tomando por base as discussões (1- Matemática Acadêmica e Matemática Escolar; 2- A Matemática Escolar: múltiplos condicionantes; e 3- Conhecimento dos conjuntos dos números naturais, racionais e reais) e os exemplos explorados pelos autores da obra, consideramos a obra intitulada de A formação matemática do professor: licenciatura e prática docente escolar muito pertinente para quem está e/ou atuará na formação de futuros professores de matemática.

\section{Referências}

BRASIL, Ministério da Educação. Base Nacional Curricular Comum. Brasília, 2018. Disponível em:

<http://basenacionalcomum.mec.gov.br/images/BNCC_EI_EF_110518_versaofinal_site.pdf> Acesso em: 23 jul. 2021. 


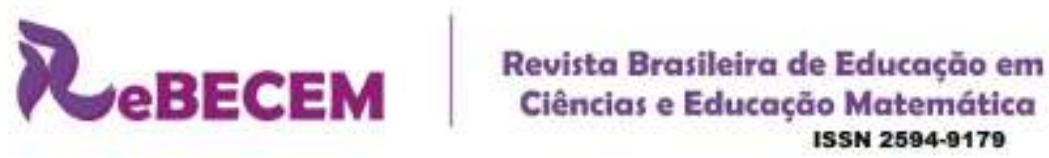

DOI: https://doi.org/10.33238/ReBECEM.2021.v.5.n.2.26886

CHEVALLARD, Y. La Transposición Didáctiva: Del saber sábio al saber enseñado.Buenos Aires: Aique, $1^{\text {a }}$. ed. 1991.

CHERVEL, A. História das disciplinas escolares: reflexões sobre um campo de pesquisa.

Teoria e Educação, Porto Alegre, v. 1, n. 2, p. 177-229, 1990.

GIRALDO, V. Formação de Professores de Matemática: para uma Abordagem Problematizada. Ciência e Cultura, São Paulo, v. 70, n. 1, p. 37-42, 2018. Disponível em:

< http://cienciaecultura.bvs.br/pdf/cic/v70n1/v70n1a12.pdf>. Acesso em: 24 jul. 2021.

MOREIRA, P. C. $3+1$ e suas (In)variantes (reflexões sobre as possibilidades de uma nova estrutura curricular na licenciatura em matemática). Bolema, Rio Claro, v. 26, n. 44, p. 1137 1150, 2012. Disponível em:

<https://www.scielo.br/j/bolema/a/r4yWF5GFmrggBdzvLxdyk4Q/abstract/?lang=pt >. Acesso 24 jul. 2021.

MOREIRA, P. C.; DAVID, M. M. M. S. A Formação matemática do Professor: licenciatura e prática docente escolar. $2^{\mathrm{a}}$ ed. Belo Horizonte: Autêntica, 2018.

Recebido em: 02 de fevereiro de 2021

Aceito em: 17 de julho de 2021 